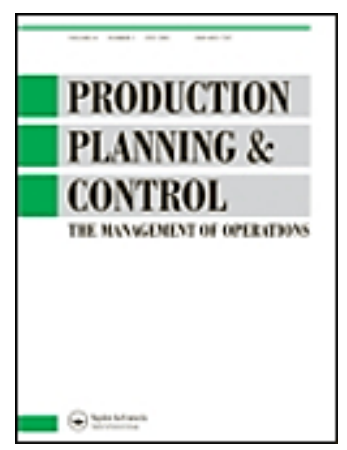

\title{
Relationships between competences and Lean Automation practices: an exploratory study
}

\begin{tabular}{|r|l|}
\hline Journal: & Production Planning \& Control \\
\hline Manuscript ID & TPPC-2020-0661.R3 \\
\hline Manuscript Type: & Research paper for Regular Issue \\
\hline Author: & 26-Jun-2021 \\
\hline & $\begin{array}{l}\text { Tomplete List of Authors: } \\
\text { Austral; Universidade Federal de Santa Catarina } \\
\text { Saurin, Tarcisio; Universidade Federal do Rio Grande do Sul, Industrial } \\
\text { Engineering and Transportation; } \\
\text { Gaiardelli, Paolo; University of Bergamo, Industrial Engineering } \\
\text { Jurgburg, Daniel; Universidad de Montevideo, Engineering faculty }\end{array}$ \\
\hline Keywords: & Lean Automation, Competences, Lean Production, Industry 4.0 \\
\hline &
\end{tabular}

\section{SCHOLARONE Manuscripts}




\title{
Relationships between competences and Lean Automation practices: an exploratory study
}

\author{
Guilherme Luz Tortorella* (gtortorella@bol.com.br) \\ The University of Melbourne, Melbourne, Australia \\ Universidad Austral, Buenos Aires, Argentina \\ Universidade Federal de Santa Catarina, Florianopolis, Brazil
}

Tarcísio A. Saurin (saurin@ufrgs.br)

Universidade Federal do Rio Grande do Sul, Porto Alegre, Brazil

Paolo Gaiardelli (paolo.gaiardelli@unibg.it)

Università Degli Studi di Bergamo, Bergamo, Italy

Daniel Jurburg (djurburg1@um.edu.uy)

Universidad de Montevideo, Montevideo, Uruguay

\section{* Corresponding author}




\begin{abstract}
Lean Automation (LA) is defined as the combined use of Lean Production (LP) practices and Industry 4.0 (I4.0) technologies. This paper investigates the pairwise relationships between the LA practices and their corresponding implementation competences. A survey-based study with 110 practitioners from manufacturing companies was conducted. Multivariate data techniques were used to analyze the responses, which were categorized according to practitioners' LP experience and I4.0 knowledge. Findings indicate that the relationships between competences and LA practices become more prominent as practitioners' LP experience increases. A contrary trend was observed when I4.0 knowledge increases. Nevertheless, commonalities were found regardless respondents' characteristics, such as: $(i)$ the significant relationships between LA practices and competences were all positive; (ii) supply chain-related LA practices are more likely to be extensively associated with all competences; and (iii) competences related to the ability of identifying, analyzing and solving problems through computer programming and data analytics were the most likely to support LA practices. To the best of our knowledge, this is the first study that empirically verifies the pairwise relationship between competences and LA practices. The understanding of this allows companies to foster and develop the proper competences on the employees, catalyzing the LA implementation.
\end{abstract}

Keywords: Lean Automation, Competences, Lean Production, Industry 4.0. 


\title{
Relationships between competences and Lean Automation practices: an
}

\section{exploratory study}

\author{
Guilherme Luz Tortorella* (gtortorella@,bol.com.br)
}

The University of Melbourne, Melbourne, Australia

Universidad Austral, Buenos Aires, Argentina

Universidade Federal de Santa Catarina, Florianopolis, Brazil

Tarcísio A. Saurin (saurin@ufrgs.br)

Universidade Federal do Rio Grande do Sul, Porto Alegre, Brazil

Paolo Gaiardelli (paolo.gaiardelli@,unibg.it)

Università Degli Studi di Bergamo, Bergamo, Italy

Daniel Jurburg (djurburg1@um.edu.uy)

Universidad de Montevideo, Montevideo, Uruguay

* Corresponding author 
Abstract

Lean Automation (LA) is defined as the combined use of Lean Production (LP) practices and Industry 4.0 (I4.0) technologies. This paper investigates the pairwise relationships between the LA practices and their corresponding implementation competences. A survey-based study with 110 practitioners from manufacturing companies was conducted. Multivariate data techniques were used to analyze the responses, which were categorized according to practitioners' LP experience and I4.0 knowledge. Findings indicate that the relationships between competences and LA practices become more prominent as practitioners' LP experience increases. A contrary trend was observed when I4.0 knowledge increases. Nevertheless, commonalities were found regardless respondents' characteristics, such as: $(i)$ the significant relationships between LA practices and competences were all positive; (ii) supply chain-related LA practices are more likely to be extensively associated with all competences; and (iii) competences related to the ability of identifying, analyzing and solving problems through computer programming and data analytics were the most likely to support LA practices. To the best of our knowledge, this is the first study that empirically verifies the pairwise relationship between competences and LA practices. The understanding of this allows companies to foster and develop the proper competences on the employees, catalyzing the LA implementation.

Keywords: Lean Automation, Competences, Lean Production, Industry 4.0.

\section{Introduction}

Driven by the start of the fourth industrial revolution, many companies have initiated their digital transformation by incorporating disruptive technologies (e.g. Internet-of-Things, cloud computing and big data analytics) into their management processes (Xu et al., 2018). The technology-oriented approach from Industry 4.0 (I4.0) may change not only the way products, processes and services are designed, performed and delivered, but also the required 
competences of the individuals (Lorenz et al., 2015; Tortorella et al., 2018). Hence, the integration of I4.0 into a company's management approach affects both the technical (e.g. practices, technologies, work routines) and sociocultural (e.g. behaviors, leadership, organizational culture) aspects of the organization (Sony and Naik, 2020).

At the same time, Lean Production (LP) has been acknowledged during the last four decades as a strategic management approach to continuously improve organizations (Stone, 2012; Leite et al., 2020). Due to the reported benefits, LP became very popular among practitioners and researchers, motivating many studies on the aspects that support its successful implementation (Jasti and Kodali, 2015). As LP excels for simple solutions derived from continuous experimentation and problem-solving activities (Womack and Jones, 2003), researchers (e.g. Bortolotti et al., 2015; Tortorella and Fogliatto, 2017; van Dun et al., 2017) have given great emphasis on the behavioral aspects that surround it. More specifically, because individuals' behaviors play a key role for sustaining LP in the long term, the underlying competences of LP have been a point of concern (Parry et al., 2010; Seidel et al., 2017).

The recent integration between I4.0 and LP has been denoted as Lean Automation (LA). The term LA was first proposed in mid 1990s, but its utilization has gained more prominence after the advent of I4.0 (Kolberg et al., 2017; Ma et al., 2017). LA represents an integrated approach that combines the technological enablers from I4.0 with the practices and principles from LP. It is noteworthy that other terms have also been used to refer to this integration between I4.0 and LP, such as 'Lean 4.0' and 'Digital Lean'. The former expresses in the broadest sense how the combination of the principles of LP with I4.0 are implemented together at different levels of the organization, in terms of process optimization, strategy implementation, technology adoption and organizational change (Mayr et al., 2018; Arcidiacono and Pieroni, 2018; Perico and Mattioli, 2020; Bittencourt et al., 2020). The latter indicates a new way to understand the concept of production according to which, the use of new digital technologies enhances access, 
analyzes and interprets massive amounts of data to detect, corrects, predicts and prevents production process behavior, thus avoiding the generation of waste and inefficiency (Powell et al., 2018; Romero et al., 2019a; 2019b; Raweewan and Kojima, 2020). The difference between LA, Digital Lean and Lean 4.0 is blurred, and the terms are often considered synonymous by practitioners and researchers. Indeed, the core idea of combining I4.0 and LP is shared by the studies that use these terms.

The investigation of how companies can benefit from such combination has been a growing research topic (Buer et al., 2018a; Tortorella and Fettermann, 2018; Bittencourt et al., 2020). Nevertheless, most studies have focused on the technical side of LA (e.g. synergy between technologies and management practices), neglecting the social implications (Pagliosa et al., 2019; Villalba-Diez et al., 2019) such as the required implementation competences. Similarly to LP, LA implementation requires certain individual competences. However, the relationship between LA practices and their corresponding competences has not yet been explored in the literature. Furthermore, as LA encompasses technological aspects derived from I4.0, there might be additional competences to be considered besides the usual LP competences which reinforces the relevance of the research gap.

To fulfil this gap, this study aims at examining how the LA practices are related to their implementation competences, which are interpreted as those arising from the joint use of LP and I4.0. We surveyed 110 Brazilian practitioners who were experienced in LP and aware of I4.0. They were asked to indicate the adoption level of LA practices (Tortorella et al., 2020a) and the perceived level of the competences of LP (Seidel et al., 2017) and I4.0 (Hecklau et al., 2016; Grzybowska and Łupicka, 2017; Łupicka and Grzybowska, 2018) on middle managers of their corresponding companies. Because the identification of this relationship is highly dependent on respondents' perception and expertise, we categorized them according to their LP experience and I4.0 knowledge. Responses were then analyzed through multivariate data 
techniques, and communalities among the analyses were sought to grasp the most relevant pairwise relationships. The contribution of this research is two-fold. First, it provides initial evidence on the competences that support the LA implementation, which is a social aspect under explored in the literature. Second, the identification of the pairwise relationships between competences and LA practices allows companies to establish training and development plans for their leaders.

\section{Literature review}

\subsection{Lean Automation}

The notion of LA first emerged by combining LP practices to Computer Integrated Manufacturing technologies (Kolberg et al., 2017). However, even if the idea of integrating automation with LP is inherent in the lean thinking fundamentals - as clearly demonstrated by the concept of autonomation (Ohno 1988) - not much attention has been paid to it (Bortolotti and Romano, 2012; Kolberg and Zühlke, 2015) until the acknowledgement of the Fourth Industrial Revolution. I4.0 has given renewed relevance to LA, whose implications are still under investigation (Yamazaki et al., 2016; Tortorella and Fettermann, 2018).

Many conceptualizations of LA are found in the literature (e.g. Yamazaki et al., 2017; Shigematsu et al., 2018; Pantano et al., 2020). Jackson et al. (2011) defined LA as the application of automation to a given activity or process, stressing robust and reliable components and minimizing overly complicated solutions. LA favors decentralized management, aiming at modular and simple arrangements (Ma et al., 2017) with higher changeability and shorter information flows (Kolberg et al., 2017). Furthermore, most of the developed LA solutions are proprietary and as such they need to be customized to individual needs (Kolberg et al., 2017). 
Several theoretical (Buer et al., 2018b) and empirical LA applications (Powell et al., 2017) have been proposed, both covering different dimensions of LP, including but not limited to JIT (Chen and Lin, 2017), Jidoka (Romero et al. 2019b) and Human Resource Management (Romero et al., 2020). An example of application is found in Spenhoff et al. (2020), which adapted the production levelling (a.k.a. heijunka) to the semi-process industry combining it with cyber-physical systems technologies. This allowed scheduling the production system as efficiently as possible, providing the necessary flexibility and minimum schedule perturbation. Another instance of application is shown in Pozzi et al. (2021), which conducted case studies in companies implementing I4.0 as a support for their continuous improvement initiatives.

The technological choices facing manufacturers are multiple and non-trivial as the industry contemplates the increasing levels of digitization and automation in readiness for the modern competitive age (Hughes et al., 2020). However, not only do the applications refer to the shopfloor but they are also extended to the supply chain level. For instance, Sony (2018) indicated the role LA plays in the vertical, horizontal and end-to-end integration of companies, suggesting a theoretical framework based on the main LP principles and I4.0 technologies. Fatorachian and Kazemi (2021) explored the impact of I4.0 on supply chain performance, while Kucukaltan et al. (2020) indicated possible changes in the logistics industry from the operational, financial, and human resources aspects. Based on a cross-sector survey performed with 147 manufacturers, Tortorella et al. (2020a) proposed a framework for LA implementation with 31 practices (see Table 1). This framework resulted from the empirical identification of significant pairwise relationships between Shah and Ward's (2007) LP measures and I4.0 technologies (National Confederation of Industry Brazil, 2016).

Another point of interest for research concerns the evolutionary process undertaken by companies implementing LA. These companies seem to initially present a more LP-oriented approach and, as the implementation advances, the focus shifts to merging technological 
solutions to LP practices (Chiarini and Kumar, 2020; Tortorella et al., 2021a). Mora et al. (2017) highlight how companies that undertake LA progressively shift their focus from hard to soft LP practices, moving from the automation of assets to automated systems supporting production and logistics processes, as well as employee training, involvement and problemsolving support.

Table 1 - LA practices (adapted from Tortorella et al., 2020a)

\subsection{LP and I4.0 competences}

Boyatzsis (2008) defines a competency as a capability and describes it as a set of related but different behaviors organized around intentions. Behaviors are manifestations of the intent, as appropriate in various situations. Marrelli (1998) adds that a competence involves measurable knowledge, skills, traits and behaviors that allow an individual to effectively perform a task. While skills are the specific learned abilities that you need to perform a given job well, competences, on the other hand, are the person's knowledge and behaviors that lead them to be successful in a job (McNeill, 2019).

LP competences are those required for the implementation of lean systems (Parry et al., 2010). These competences are particularly important to those professionals holding formal or informal leadership roles, as these may coach others in the company and facilitate the dissemination of the expected behaviors and mental models (Bortolotti et al., 2015; Camuffo and Gerli, 2018). According to Yukl (2010), the acquisition and deployment of competences depend on three main factors: personal attributes, management systems that allow for the use of the competences, and organizational context. Seidel et al. (2019) discuss how these three factors play out in lean leadership. For instance, personal attributes of lean leaders include humility, 
honesty, and discipline. An example of mechanism of influence adopted in lean systems refers to shop floor daily management meetings supported by visual devices. In turn, relevant organizational context can account for the level of education of the workforce and company's size. Seidel et al. (2017) identified, based on a literature review and interviews with experts, key competences of lean leaders. Those authors carried out a survey with 91 companies and found that the use of those competences was positively associated with the development stage of the lean system.

With regards to I4.0, a few works have explored the required competences to cope with the challenges related to its new technologies and processes. Hecklau et al. (2016) developed an I4.0 competence model composed of four categories of competences: $(i)$ technical, (ii) methodological, (iii) social and (iv) personal. Grzybowska and Łupicka (2017) proposed eight core managerial competences to support I4.0 adoption. Łupicka and Grzybowska (2018) refined the study by re-classifying those competences in three categories (social, technical and managerial) and comparing the expectations of practitioners, scientists, and students. Pinzone et al. (2017) focused on the evolution of technical skills in the I4.0 context, providing qualitative insights raised from a variety of manufacturers in Northern Italy.

LP and I4.0 competences present a certain level of overlap, especially with respect to social competences. In turn, there are relevant differences on the technical competences, since I4.0 literature emphasizes data analytics competences. For the purpose of assessing the relationships between the LA practices and competences, we adapted and consolidated in Table 2 the competences of LP, proposed by Seidel et al. (2017) and Camuffo and Gerli (2018), and I4.0, derived from Hecklau et al. (2016), Grzybowska and Lupicka (2017) and Lupicka and Grzybowska (2018). These 14 competences provide the basis for our study, whose theoretical model is displayed in Figure 1. It is worth noting that these 14 competences were combined 
into one main dimension, namely LA competences, following the rationale that LA integrates I4.0 technologies into LP practices (Tortorella et al., 2021b).

Table 2 - LP and I4.0 competences

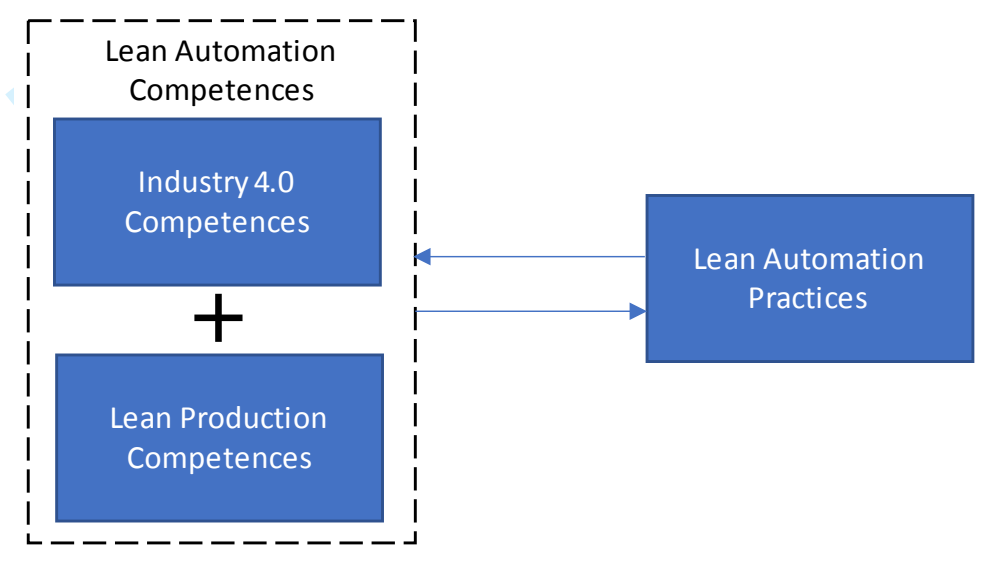

Control Variables:

1- Practitioners' experience with Lean Production

2- Practitioners' knowledge on Industry 4.0

Figure 1 - Theoretical model investigated

\section{Method}

\subsection{Research strategy}

This research examines how the LA competences, which stem from LP and I4.0, relate to LA practices. As this is an exploratory research, we adopted an empirical approach as part of the methodological procedure, which allows obtaining knowledge through direct and indirect observation or experience (Goodwin, 2005). To collect data and quantify the empirical evidence, we adopted the survey method with non-random choice of respondents. The survey method presents many advantages, such as high level of representativeness, low cost, good 
statistical significance, and a standardized stimulus to all respondents (Montgomery, 2013). Hence, the proposed method was comprised of three main steps: $(i)$ instrument development, (ii) sample selection and data collection, and (iii) data analysis. These steps are subsequently detailed.

\subsection{Instrument development}

The questionnaire had three parts. Initially, we collected data on respondents' profile (role, years of lean experience and I4.0 knowledge) and their organizations (tier level, size and sector). Guidelines were provided to respondents to help them define their own level of knowledge on I4.0, in order to reduce subjectivity. We asked respondents to rate themselves as basic (i.e. they were able of describing what the main I4.0 technologies are and their benefits, in general terms, without further deepening) or moderate/advanced (i.e. they could engage in a technical discussion about I4.0 adoption or lead its adoption in multiple contexts). Then, in the second part of the questionnaire, respondents were asked to indicate the adoption level of the 31 LA measures proposed by Tortorella et al. (2020a) in their organizations (see Table 1). For that, we used a five-point Likert scale, ranging from 1 (not used) to 5 (fully adopted). In the third part of the questionnaire, we consolidated the sixteen LP competencies proposed by Seidel et al. (2017) into twelve, since we interpreted that four of them were more properly related to LP principles instead LP competences. Then, we combined the LP competences with the I4.0 competences suggested by Hecklau et al. (2016), Grzybowska and Łupicka (2017), and Łupicka and Grzybowska (2018), displayed in Table 2. Respondents were asked to indicate in a 5-point scale (1 for 'not developed' and 5 for fully developed) the level of those competences considering middle managers in their companies. According to Holmemo and Ingvaldsen (2016), van Dun et al. (2017) and Tortorella et al. (2019), middle managers play a key role in executing the strategic guidelines and implementing the improvement initiatives. 
Hence, their competences are relevant for the success of a lean implementation, justifying the focus on this role.

Two senior academicians ( $>20$ years working with LP) and one experienced practitioner $(>10$ years) pre-tested the instrument to verify its face and content validity (Kothari, 2004). These experts recommended a few changes in taxonomy and wording of the questions. Additionally, some procedures were performed to curb potential common method variance (Huber and Power, 1985). Regarding the design of the questionnaire, dependent variables were displayed far from independent ones (Podsakoff and Organ, 1986). An initial statement informing about the anonymous and confidential nature of the study, and the fact that there were no right answers was inserted in the questionnaire (Podsakoff et al., 2003).

\subsection{Sample selection and data collection}

A non-random approach with predefined selection criteria was used for sampling (Smith, 1983). The utilization of non-random respondents that meet certain criteria to collect data and quantify empirical evidence is a common approach in similar studies (e.g. Tortorella et al., 2020a; 2021), and can help answering research questions whose topic is still at its early stages. Respondents should be experienced in LP and aware of I4.0 technologies. Due to the limited amount of companies adopting both LP and initiated at I4.0 (Tortorella and Fettermann, 2018), we included companies from different industrial sectors in the sample. Additionally, even though LP implementation is more common in high-volume and discrete-parts manufacturers, Marodin et al. (2015) highlighted that the pervasiveness of its practices across different industries is not known, justifying the cross-industry sample.

Because the researchers have already developed a large network with organizations through previous collaboration activities (e.g. consultancy, research and education), the identification 
of potential respondents was facilitated. A pre-selection was carried out by identifying potential respondents among people with both theoretical and practical experience in LP and at least the theoretical basis on automation. The questionnaire was initially sent to 658 practitioners from companies located in Brazil during October and November 2020. From those, 110 responses were received, resulting in a response rate of $16.7 \%$. As shown in Table 3, 56.4\% of the sample was from companies with less than 500 employees and from tiers 1 or 2 in their respective supply chain. Participants were predominantly from the chemical and automotive sectors. The majority of respondents were engineers or analyst in their companies (38.2\%), and claimed to have a moderate or advanced knowledge on I4.0 (51.8\%). In terms of LP experience, the sample was perfectly balanced between those who had more than 5 years of experience and the ones with less than 5 years.

As an additional verification for common method bias, we conducted a statistical analysis using Harman's single-factor test (Malhotra et al., 2006) including all study measures. Results pointed to a first factor explaining $29.6 \%$ of the total variance, which indicated that no single factor accounted for most of the variance in responses. Thus, we disregarded issues related to common method bias.

Table 3 - Sample characteristics

\subsection{Data analysis}

Due to our study's purpose, a set of partial correlation analyses for each pairwise relationship between competences and LA practices was conducted. Partial correlations allow to control the effect of the remaining items on the pairwise analysis of a given pairwise relationship (Baba et al., 2004). Partial correlations assess the intensity of the linear relationship between two items, also considering their association with the other variables. This approach is specifically proper for cases in which the relationship between two items may be affected by their relationships 
with the remaining ones (Legendre and Legendre, 2012). This method enabled the investigation of the relationship between all possible pairwise combinations between competences and LA practices. It is important to mention that the effect of multicollinearity on the estimated coefficients was verified through the variance inflation factors (VIF) for all variables, whose results were all below 5, indicating that multicollinearity was not an issue (Belsley et al., 2005).

This approach was applied to both respondents' LP experience and I4.0 knowledge. For LP experience, respondents were divided into low-experienced $(<5$ years $)$ and high-experienced ( $>5$ years). For I4.0 knowledge, we divided the sample into respondents who claimed having a basic knowledge and the ones who indicated a moderate or advanced knowledge on I4.0. Thus, four partial correlation analyses for the 14 competences and 31 LA practices were undertaken, totaling 1,736 pairwise analyses investigated. The sample's mean values and standard deviation for the competences and LA practices according to each level are presented in Appendix.

\section{Results}

Table 4 shows the results for partial correlations between LA competences and LA practices for less experienced ( $<5$ years) respondents on LP implementation. From 434 possible correlations, 385 significant and positive partial correlations ( $p$-value $<0.05$ ) were found. From the 31 LA practices, 15 were significantly correlated with all the 14 competences. In opposition, practice $l a_{21}$ (extensive use of statistical techniques to reduce process variance through digital sensors and remote control of production integrated with collaborative engineering systems, which identify abnormal product/operating conditions) was the one with the lowest number of significant partial correlation coefficients with the competences ( 5 in 
total). This may be due to the narrow applicability of this LA practice, which implies a narrow set of corresponding competences.

In terms of competences, 4 out of $14\left(c_{2}, c_{12}, c_{13}\right.$ and $\left.c_{14}\right)$ were partially correlated with all LA practices, while $c_{8}$ (identify and manage barriers during improvement initiatives implementation journey) was the least correlated competence (16 in total). This can result from the wide scope of this competence, which is useful for the LA implementation project as a whole, while having a diffuse and weak relationship with specific LA practices.

It is also worth mentioning that we found only four strong pairwise partial correlations, whose coefficients were greater than 0.7 (Baba et al., 2004). Two of them involved $c_{13}$ (develop data processing and analytics) and the other two encompassed $c_{14}$ (put in practice statistical tools), which are competences derived from I4.0.

Table 5 displays the partial correlation coefficients when utilizing data from respondents more experienced in LP ( $>5$ years). The number of significant partial correlations increased from 385 to 395 , and twelve strong correlations were found between six LA practices and seven LA competences. Regarding LA practices, 12 out of 31 had significant coefficients with all the 14 competences, while la $a_{20}$ (large number of equipment/processes on shop floor are currently under statistical process control and monitored through digital sensors integrated into collaborative engineering systems) was correlated with only 7 competences. Interestingly, practices $l a_{5}, l a_{6}$ and $l a_{9}$ presented three strong partial correlations each. With respect to competences, four of them $\left(c_{1}, c_{5}, c_{11}\right.$ and $\left.c_{13}\right)$ were significantly correlated with all LA practices, and $c_{9}$ (practice continuous improvement as an interrelated system of principles and practices) was the least pervasive one being significantly correlated with 19 practices. Competence $c_{5}$ (provide value-added information clearly and objectively) was involved in three strong partial correlations with LA practices. 
Table 4 - Partial correlation between LA practices and competences using perceptions of practitioners with less than 5 years of LP experience $(n=55)$

Table 5 - Partial correlation between LA practices and competences using perceptions of practitioners with more than 5 years of LP experience $(n=55)$

When considering I4.0 knowledge as the control variable, results were slightly different. Table 6 reports the partial correlation coefficients for the analysis using respondents with basic knowledge on I4.0. 399 significant coefficients were found $(91.9 \%$ of total pairwise relationships), which was the highest total number of significant partial correlations among the four analyses performed. However, only one strong partial correlation was obtained.

Fourteen LA practices were significantly correlated with all LA competences. Similarly to what was found in the analysis with respondents less experienced with LP, $l a_{21}$ was the practice with the lowest number of significant correlations with competences ( 8 in total). As for competences, half of them were correlated $(p$-value $<0.05)$ with all LA practices. The one with the lowest number of significant correlations was $c_{9}$, which was also observed in the results obtained for practitioners with more than 5 years of LP experience.

Finally, Table 7 shows the outcomes for the partial correlation analysis using responses from practitioners that had moderate or advanced knowledge on I4.0, according to their selfassessment. In total, 339 significant partial correlations were obtained $(78.1 \%$ of possible pairwise correlations), which was the lowest number among all four analyses. Five LA practices were correlated with all competences, while $l a_{20}$ was seems to be correlated with only three which is similar to what was found in the analysis with more LP experienced respondents. In terms of competences, only $c_{14}$ was correlated with all LA practices, while $c_{10}$ (develop 
actions that, based on ethical principles, respect the community, the environment and the workers' safety) had a significant correlation with fourteen practices. Two strong partial correlation coefficients were found.

Table 6 - Partial correlation between LA practices and competences using perceptions of practitioners with Basic knowledge on I4.0 $(n=53)$

Table 7 - Partial correlation between LA practices and competences using perceptions of practitioners with Moderate or Advanced knowledge on I4.0 $(n=57)$

\section{Discussion}

Results for the pairwise relationships between LA competences and practices appear to have contrary trends when considering respondents' background. On one hand, as respondents' LP experience increases, the intensity of such relationships seems to increase as well. Not only the number of significant correlations was larger, but also the number of strong correlations. Experienced practitioners tend to be more prepared to judge not only the tangible aspects of a lean implementation, such as the adoption level of LA practices (Plonka, 1997; Wickramasinghe and Wickramasinghe, 2020; Tortorella et al., 2020b), but also the presence of intangible and more subtle factors (Carleysmith et al., 2009; Jayaraman et al., 2012), such as the competences of their companies' middle managers. Our findings corroborate to that. Further, the perception of respondents who are more experienced in LP seems to be comprehensive and systems-oriented, since 30 out 31 LA practices were supported by at least 10 out of the 14 competences. This suggests that, according to these respondents' perception, the implementation of LA practices is positively associated with a diversity of competences either from LP or I4.0. 
On the other hand, when respondents' I4.0 knowledge is higher, the relationship between competences and LA practices is less evident. This outcome may be due to an overly technical view of I4.0, which tends to be more reductionist than the systems-oriented LP perspective. Another possibility is that more knowledgeable I4.0 practitioners are more likely to have a more critical perspective of competences and practices associated with I4.0. This interpretation can be associated with May and Kruger's (1988) indications, which were later explored in the organizational context by Thompson and Martin (2010). These authors propose four stages of competence development: (i) unconsciously incompetent, (ii) consciously incompetent, (iii) consciously competent and (iv) unconsciously competent. Practitioners with moderate or advanced I4.0 knowledge might be more critical about their opinions, leading to more conservative results for the pairwise relationship between competences and LA practices. Regardless respondents' LP experience and I4.0 knowledge, several commonalities were found in the pairwise relationships between competences and practices. First, all significant partial correlations had positive coefficients, which indicates the positive correlation between the competences and practices. This converges to the indications from Raweewan and Kojima (2020), which highlight the need for developing additional skills for the proper digitalization of LP. Second, as shown in Table 8, 324 pairwise relationships were found significant in all four analyses, suggesting that they occur independently of the respondents' characteristics. There seems to be a consensus that practices $l a_{3}, l a_{5}, l a_{6}$ and $l a_{9}$ are correlated with all competences. All these LA practices are supply chain-oriented; i.e. they help improving the relationship with either suppliers or customers. In terms of competences, $c_{2}, c_{12}, c_{13}$ and $c_{14}$ were the ones with the highest number of similar significant correlations considering all four analyses. While $c_{2}$ derives from LP (Seidel et al., 2019), $c_{12}, c_{13}$ and $c_{14}$ originate from I4.0 (Hecklau et al., 2016; Grzybowska and Łupicka, 2017; Łupicka and Grzybowska, 2018). In common, they refer to individual's ability of identifying, analyzing and solving problems 
through robust methods. This emphasizes the relevance of developing such competences in middle managers of companies undergoing a LA implementation. Such finding is aligned with indications from Spear $(2004 ; 2008)$, which stresses the need for training lean leaders to be good problem-solvers. Our results build on this by incorporating computer programming- and data analytics-related competences as a support for the digitization required by the LA implementation. Therefore, we can summarize the main findings of our research as follows:

a) All significant pairwise relationships between LA practices and LA competences were positive;

b) Supply chain-related LA practices are more likely to be extensively associated with all competences. This may stem from the complexity of supply chain management, which involves coordination between a number of diverse stakeholders, often under conditions of uncertainty; and

c) Competences related to the identification, analysis, and problem-solving through methods that incorporate computer programming and data analytics were the ones mostly associated with LA practices.

Table 8 - Consolidation of the pairwise partial correlation between LA practices and competences

\section{Conclusions}

This study aimed at investigating the pairwise relationships between LA competences and LA practices. Responses from 110 practitioners were classified according to two respondents' characteristics: LP experience (i.e. $<5$ years and $>5$ years) and I4.0 knowledge (i.e. basic and moderate/advanced). Four partial correlation analyses were performed, being one for each level of each characteristic. 
From a theoretical perspective, our study provides initial evidence on the competences that support the LA implementation. Since the integration of I4.0 technologies into LP practices is a recent phenomenon, literature on this matter is still scarce. Our results indicate that LA is associated with the same competences of LP but requires the addition of specific I4.0 competences such as ' $c_{13}$-develop data processing and analytics' and ' $c_{14}$-put in practice statistical tools'. Although LP implementation already stressed the need for problem-solving competences, with the integration of I4.0 technologies the amount of data collected, stored, shared, processed and analyzed significantly increases, demanding the development of more sophisticated competences to manage it. Hence, certain competences that so far had only been mentioned in I4.0 studies were significantly correlated with LA practices, evidencing that the implementation of LA practices requires I4.0 competences. This finding suggests that, although LA derives from LP, its approach has some specificities that may represent the next production paradigm.

With regards to practical contributions, our research provides companies some guidance on the competences necessary to an effective LA implementation. The identification of the pairwise relationship between LA competences and LA practices allows companies to customize the development of their staff, especially middle managers, so that they present the competences that are more likely to support the desired LA practices. Since some competences may require a long time to be developed, our results allow companies to anticipate potential issues based on the focus of their LA implementation, thus providing managers guidelines that help them anticipate which individual competences are necessary to successfully adopt the LA practices of interest. Additionally, it was observed that when companies are seeking LA implementation at a supply chain level, the adoption of the corresponding practices may demand a diversified set of competences. This must draw the attention of management so that they can assess whether they have settled the proper competences before expending any effort. 
This work has some limitations that are worth mentioning. The competences encompassed here derived from previous studies on both LP and I4.0. However, as the understanding on LA implementation advances, there might be need for additional competences. To investigate that, it is recommended the development of longitudinal studies in which researchers could verify the need for further competences as the LA is implemented. Moreover, companies may not be able to concomitantly develop all competences to support LA implementation. Because our study did not provide any evidence on the interrelationship among the competences, future studies should check whether there is a precedence of competences; i.e. a development sequence of the competences that would favor a smoother LA implementation. Another opportunity refers to a potential moderating effect of the control variables (LP experience and knowledge on I4.0) on the relationship between LA practices and competences. Future studies could analyze such moderation to check whether there is any significant differences between the categories of each control variable, which was not addressed here. Finally, although we carefully managed the data to avoid common method bias, larger sample sizes with diversified contextual characteristics would allow the utilization of more sophisticated data analysis techniques (e.g. structural equations modelling). This could lead to additional findings that were not able to be raised with our approach.

\section{References}

Arcidiacono, G., \& Pieroni, A. (2018). The revolution lean six sigma 4.0. International Journal on Advanced Science, Engineering and Information Technology, 8(1), 141-149.

Baba, K., Shibata, R., \& Sibuya, M. (2004). Partial correlation and conditional correlation as measures of conditional independence. Australian \& New Zealand Journal of Statistics, 46(4), 657-664.

Belsley, D., Kuh, E., \& Welsch, R. (2005). Regression diagnostics: identifying influential data and sources of collinearity. John Wiley \& Sons (Vol. 571), New York. 
1

2

3

4

5

6

7

8

9

10

Bittencourt, V., Alves, A., \& Leão, C. (2020). Industry 4.0 triggered by Lean Thinking: insights from a systematic literature review. International Journal of Production Research, (forthcoming).

Bortolotti, T., Boscari, S., \& Danese, P. (2015). Successful lean implementation: Organizational culture and soft lean practices. International Journal of Production Economics, 160, 182-201.

Bortolotti, T., \& Romano, P. (2012). 'Lean first, then automate': a framework for process improvement in pure service companies. A case study. Production Planning \& Control, 23(7), 513-522.

Boyatzsis, R. (2008). Competencies in the twenty-first century. Journal of Management Development, 27(1), 512.

Buer, S., Strandhagen, J., \& Chan, F. (2018a). The link between Industry 4.0 and lean manufacturing: mapping current research and establishing a research agenda. International Journal of Production Research, 56(8), 29242940.

Buer, S., Fragapane, G., \& Strandhagen, J. (2018b). The Data-Driven Process Improvement Cycle: Using Digitalization for Continuous Improvement. IFAC-PapersOnLine, 51(11), 1035-1040.

Camuffo, A., \& Gerli, F. (2018). Modeling Management Behaviours in Lean Production Environments. International Journal of Operations \& Production Management, 38(2), 403-423.

Carleysmith, S., Dufton, A., \& Altria, K. (2009). Implementing Lean Sigma in pharmaceutical research and development: a review by practitioners. $R \& D$ Management, 39(1), 95-106.

Chen, T., \& Lin Y.-C. (2017). Feasibility Evaluation and Optimization of a Smart Manufacturing System Based on 3D Printing: A Review. International Journal of Intelligent Systems, 32(4), 394- 413.

Chiarini, A., \& Kumar, M. (2020). Lean Six Sigma and Industry 4.0 integration for Operational Excellence: evidence from Italian manufacturing companies. Production Planning \& Control, (forthcoming).

Fatorachian, H., \& Kazemi, H. (2021). Impact of Industry 4.0 on supply chain performance. Production Planning \& Control, 32(1), 63-81.

Goodwin, C. (2005). Research in Psychology: methods and design. John Wiley \& Sons, Inc., New York. Grzybowska, K., \& Łupicka, A. (2017). Key competencies for Industry 4.0. Economics \& Management Innovations, 1(1), 250-253. 
Hecklau, F., Galeitzke, M., Flachs, S., \& Kohl, H. (2016). Holistic approach for human resource management in Industry 4.0. Procedia CIRP, 54(1), 1-6.

Holmemo, M., \& Ingvaldsen, J. (2016). Bypassing the dinosaurs? How middle managers become the missing link in lean implementation. Total Quality Management \& Business Excellence, 27(11-12), 1332-1345.

Huber, G., \& Power, D. (1985). Retrospective reports of strategic-level managers: guidelines for increasing their accuracy. Strategic Management Journal, 6, 171-180.

Hughes, L., Dwivedi, Y., Rana, N., Williams, M., \& Raghavan, V. (2020). Perspectives on the future of manufacturing within the Industry 4.0 era. Production Planning \& Control, (forthcoming).

Jackson, M., Hedelind, M., Hellström, E., Granlund, A., \& Friedler, N. (2011). Lean automation: Requirements and solutions for efficient use of robot automation in the swedish manufacturing industry. International Journal of Engineering Research \& Innovation, 3(2), 36-43.

Jasti, N., \& Kodali, R. (2015). Lean production: literature review and trends. International Journal of Production Research, 53(3), 867-885.

Jayaraman, K., Leam Kee, T., \& Lin Soh, K. (2012). The perceptions and perspectives of Lean Six Sigma (LSS) practitioners: An empirical study in Malaysia. The TQM Journal, 24(5), 433-446.

Kolberg, D., Knobloch, J., \& Zühlke, D. (2017). Towards a lean automation interface for workstations. International Journal of Production Research, 55(10), 2845-2856.

Kolberg, D., \& Zühlke, D. (2015). Lean automation enabled by industry 4.0 technologies. IFAC-PapersOnLine, 48(3), 1870-1875.

Kothari, C. (2004). Research methodology: Methods and techniques. New Age International, London.

Kucukaltan, B., Saatcioglu, O., Irani, Z., \& Tuna, O. (2020). Gaining strategic insights into Logistics 4.0: expectations and impacts. Production Planning \& Control, (forthcoming).

Legendre, P., \& Legendre, L. (2012). Numerical Ecology, Elsevier (Vol. 24), London.

Leite, H., Radnor, Z., \& Bateman, N. (2020). Meaningful inhibitors of the lean journey: a systematic review and categorisation of over 20 years of literature. Production Planning \& Control, (forthcoming).

Lorenz, M., Rüßmann, M., Strack, R., Lueth, K. L., \& Bolle, M. (2015). Man and machine in industry 4.0: How will technology transform the industrial workforce through 2025. The Boston Consulting Group, 2. 
1

2

3

4

5

6

7

8

9

10

Łupicka, A., \& Grzybowska, K. (2018). Key Managerial Competencies for Industry 4.0-Practitioners', Researchers' and Students' Opinions. Logistics and Transport, 39.

Ma, J., Wang, Q., \& Zhao, Z. (2017). SLAE-CPS: Smart lean automation engine enabled by cyber-physical systems technologies. Sensors, 17(7), 1500.

Malhotra, N., Birks, D., \& Wills, P. (2006). Marketing research: an applied approach. Pearson Education, London.

Marrelli, A. (1998). An introduction to competency analysis and modeling. Performance Improvement, 37(5), 817.

Marodin, G., Saurin, T., Tortorella, G., Denicol, J. (2015). How context factors influence lean production practices in manufacturing cells. The International Journal of Advanced Manufacturing Technology, 79(5-8), 1389-1399.

May, G., \& Kruger, M. (1988). The manager within. Personnel Journal, 66, 57-65.

Mayr, A., Weigelt, M., Kühl, A., Grimm, S., Erll, A., Potzel, M., \& Franke, J. (2018). Lean 4.0-A conceptual conjunction of lean management and Industry 4.0. Procedia CIRP, 72, 622-628.

McNeill, J. (2019). Skills vs. competencies - what's the difference, and why should you care? Hays Worldwide. Available at: https://social.hays.com/2019/10/04/skills-competencies-whats-the-difference/ (accessed on November $\left.20^{\text {th }} 2020\right)$.

Montgomery, D. (2013). Design and analysis of experiments. Wiley, New York.

Mora, E., Gaiardelli P., Resta, B. \& Powell D. (2017). Exploiting Lean Benefits Through Smart Manufacturing: A Comprehensive Perspective. IFIP Advances in Information and Communication Technology, 127-134. Springer, Cham.

National Confederation of Industry Brazil (2016). Industry 4.0: a new challenge for Brazilian industry. CNI Indicators, 17(2).

Ohno, T. (1988). Toyota Production System: Beyond Large-scale Production. Cambridge, Mass: Productivity Press.

Pagliosa, M., Tortorella, G., \& Ferreira, J. (2019). Industry 4.0 and Lean Manufacturing: A systematic literature review and future research directions. Journal of Manufacturing Technology Management, (forthcoming). 
Pantano, M., Regulin, D., Lutz, B., \& Lee, D. (2020). A human-cyber-physical system approach to lean automation using an industrie 4.0 reference architecture. Procedia Manufacturing, 51, 1082-1090.

Parry, G., Mills, J., \& Turner, C. (2010). Lean competence: integration of theories in operations management practice. Supply Chain Management, 15(3), 216-226.

Perico, P., \& Mattioli, J. (2020). Empowering process and control in lean 4.0 with artificial intelligence. In 2020 Third International Conference on Artificial Intelligence for Industries (AI4I) (pp. 6-9). IEEE.

Pinzone, M., Fantini, P., Perini, S., Garavaglia, S., Taisch, M., \& Miragliotta, G. (2017). Jobs and skills in Industry 4.0: An exploratory research. In IFIP International Conference on Advances in Production Management Systems (pp.282-288). Springer, Cham.

Plonka, F. (1997). Developing a lean and agile work force. Human Factors and Ergonomics in Manufacturing \& Service Industries, 7(1), 11-20.

Podsakoff, P., \& Organ, D. (1986). Self-reports in organizational research: problems and prospects. Journal of Management, 12(4), 531-544.

Podsakoff, P., MacKenzie, S., Lee, J., \& Podsakoff, N. (2003). Common method biases in behavioral research: a critical review of the literature and recommended remedies. Journal of Applied Psychology, 88(5), 879.

Powell, D., Romero, D., Gaiardelli, P., Cimini, C., \& Cavalieri, S. (2018). Towards digital lean cyber-physical production systems: Industry 4.0 technologies as enablers of leaner production. IFIP International Conference on Advances in Production Management Systems, 353-362. Springer, Cham.

Pozzi, R., Rossi, T., \& Secchi, R. (2021). Industry 4.0 technologies: critical success factors for implementation and improvements in manufacturing companies. Production Planning \& Control, (forthcoming).

Raweewan, M., \& Kojima, F. (2020). Digital Lean Manufacturing-Collaborative University-Industry Education in Systems Design for Lean Transformation. Procedia Manufacturing, 45, 183-188.

Romero, D., Gaiardelli, P., Powell, D., Wuest, T., \& Thürer, M. (2019a). Rethinking Jidoka Systems under Automation \& Learning Perspectives in the Digital Lean Manufacturing World. IFAC-PapersOnLine, 52(13), $899-903$. 
1

2

3

4

5

6

7

8

9

Romero, D., Gaiardelli, P., Powell, D., Wuest, T., \& Thürer, M. (2019b). Total Quality Management and Quality Circles in the Digital Lean Manufacturing World. IFIP International Conference on Advances in Production Management Systems (IFIP AICT 566 - Part 1), 353-362. Springer, Cham.

Romero, D., Gaiardelli, P., Wuest, T., Powell, D., Thürer, M. (2020). New Forms of Gemba Walks and their Digital Tools in the Digital Lean Manufacturing World. IFIP Advances in Information and Communication Technology (IFIP AICT 592 - Part 2), 432-440. Springer, Cham.

Seidel, A., Saurin, T.A., Marodin, G.A., \& Ribeiro, J. (2017). Lean leadership competencies: a multi-method study. Management Decision, 55(10), 2163-2180.

Seidel, A., Saurin, T., Tortorella, G., \& Marodin G. (2019). How can general leadership theories help to expand the knowledge of lean leadership? Production Planning \& Control, 30(16), 1322-36.

Shah, R., \& Ward, P. (2007). Defining and developing measures of lean production. Journal of Operations Management, 25(4), 785-805.

Shigematsu, K., Yamazaki, Y., Kato, S., Kojima, F., \& Takata, S. (2018). Process-independent workstation layout for lean automation. CIRP Annals, 67(1), 475-478.

Smith, T. (1983). On the validity of inferences from non-random samples. Journal of the Royal Statistical Society: Series A, 146(4), 394-403.

Sony, M. (2018). Industry 4.0 and lean management: a proposed integration model and research propositions. Production \& Manufacturing Research, 6(1), 416-432.

Sony, M., \& Naik, S. (2020). Industry 4.0 integration with socio-technical systems theory: A systematic review and proposed theoretical model. Technology in Society, 101248.

Spear, S. (2008). Chasing the Rabbit: How Market Leaders Outdistance the Competition and How Great Companies Can Catch Up and Win, Foreword by Clay Christensen. New York: McGraw Hill Professional.

Spear, S. (2004). Learning to lead at Toyota. Harvard Business Review, 82(5), 78-91.

Spenhoff, P., Wortmann, J., \& Semini, M. (2020). EPEC 4.0: an Industry 4.0-supported lean production control concept for the semi-process industry. Production Planning \& Control, (forthcoming).

Stone, K. (2012). Four decades of lean: a systematic literature review. International Journal of Lean Six Sigma, $3(2), 112-132$. 
Thompson, J., \& Martin, F. (2010). Strategic Management: Awareness \& Change. London: Cengage Learning EMEA.

Tortorella, G., \& Fettermann, D. (2018). Implementation of Industry 4.0 and lean production in Brazilian manufacturing companies. International Journal of Production Research, 56(8), 2975-2987.

Tortorella, G., \& Fogliatto, F. (2017). Implementation of lean manufacturing and situational leadership styles: An empirical study. Leadership \& Organization Development Journal, 38(7), 946-968.

Tortorella, G., Miorando, R., Caiado, R., Nascimento, D., \& Portioli Staudacher, A. (2018). The mediating effect of employees' involvement on the relationship between Industry 4.0 and operational performance improvement. Total Quality Management \& Business Excellence, (forthcoming).

Tortorella, G., Narayanamurthy, G., \& Thurer, M. (2021a) Identifying pathways to a high-performing lean automation implementation: An empirical study in the manufacturing industry. International Journal of Production Economics, 231, 107918.

Tortorella, G., Pradhan, N., Macias de Anda, E., Trevino Martinez, S., Sawhney, R., \& Kumar, M. (2020b). Designing lean value streams in the fourth industrial revolution era: proposition of technology-integrated guidelines. International Journal of Production Research, (forthcoming).

Tortorella, G., Saurin, T., Godinho Filho, M., Samson, D., \& Kumar, M. (2021b). Bundles of Lean Automation practices and principles and their impact on operational performance. International Journal of Production Economics, 235, 108106.

Tortorella, G., Sawhney, R., Jurburg, D., de Paula, I.C., Tlapa, D., \& Thurer, M. (2020a). Towards the proposition of a Lean Automation framework: Integrating Industry 4.0 into Lean Production. Journal of Manufacturing Technology Management, (forthcoming).

Tortorella, G., van Dun, D. \& Almeida, A. (2019). Leadership behaviors during lean healthcare implementation: a review and longitudinal study. Journal of Manufacturing Technology Management, 31(1), 193-215.

Van Dun, D., Hicks, J., \& Wilderom, C. (2017). Values and behaviors of effective lean managers: Mixed-methods exploratory research. European Management Journal, 35(2), 174-186.

Villalba-Diez, J., Zheng, X., Schmidt, D., \& Molina, M. (2019). Characterization of industry 4.0 lean management problem-solving behavioral patterns using EEG sensors and deep learning. Sensors, 19(13), 2841. 
Wickramasinghe, V., \& Wickramasinghe, G. (2020). Effects of HRM practices, lean production practices and lean duration on performance. The International Journal of Human Resource Management, 31(11), 1467-1512.

Womack, J., \& Jones, D. (2003). Lean thinking — banish waste and create wealth in your corporation. New York: Simon \& Schuster ( $2^{\text {nd }}$ ed. $)$.

Xu, L., Xu, E., \& Li, L. (2018). Industry 4.0: state of the art and future trends. International Journal of Production Research, 56(8), 2941-2962.

Yamazaki, Y., Shigematsu, K., Kato, S., Kojima, F., Onari, H., \& Takata, S. (2017). Design method of material handling systems for lean automation-Integrating equipment for reducing wasted waiting time. CIRP Annals, 66(1), 449-452.

Yamazaki, Y., Takata, S., Onari, H., Kojima, F., \& Kato, S. (2016). Lean automation system responding to the changing market. Procedia CIRP, 57, 201-206.

Yukl, G. (2010). Leadership in Organizations. New Jersey: Prentice Hall.

Guilherme Luz Tortorella is Associate Professor of the Department of Systems and Production Engineering of the Universidade Federal de Santa Catarina, Brazil. He is the Head of Research of the Productivity and Continous Improvement Lab and the Editor-in-Chief of Journal of Lean Systems. He is one of the founders of the Brazilian Conference on Lean Systems and has more than 18 years with practical and academic experience with manufacturing and operations management.

Tarcisio A. Saurin is an Associate Professor at the Industrial Engineering Department of the

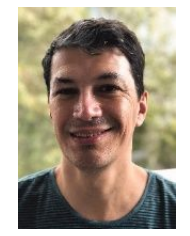
Universidade Federal do Rio Grande do Sul (Brazil). He has a BS in Civil Engineering, MS in Construction Management, and $\mathrm{PhD}$ in Industrial Engineering. He was a visiting scholar at the University of Salford (UK) and at Macquaire University, at the Australian Institute of Health Innovation. His main research interests are related to the modelling and management of complex socio-technical systems, resilience engineering, safety management, lean production, process improvement, and performance measurement. He has carried out research and consulting projects on these topics in healthcare, construction, electricity distribution, and manufacturing. 


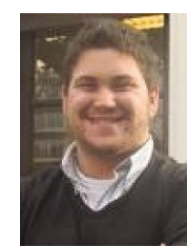

Paolo Gaiardelli is Associate Professor at the Department of Management, Information and Production Engineering of the University of Bergamo. His main teaching and research subjects mainly focus on Production and Service Management, with a specific interest in Lean Management. Recently his research interests have extended to the exploration of the role of lean management with reference to the main trends in the Operations, including sustainable and behavioural operations, digitalization and servitization of manufacturing. In particular, he is involved in studying how the adoption of lean paradigms increases the efficiency and effectiveness of Product Service Systems design, development and management.

Durburg is currently a Professor of the Faculty of Engineering of the University of Montevideo, Uruguay. He is director of the Global Supply Program, which is carried out in collaboration with the University of Pittsburgh, and an active researcher at the initiation level within the SNI of ANII. His areas of interest comprehend continuous improvement processes within companies and supply chain management. 
Table 1 - LA practices (adapted from Tortorella et al., 2020a)

$l a_{1} \quad \begin{aligned} & \text { Suppliers are directly } \\ & \text { and digital sensors. }\end{aligned}$

$l a_{2}$ Our key suppliers deliver to plant on Just-In-Time (JIT) aided by remote control of production, digital interfaces and Internet-of-Things (IoT)

$l a_{3} \quad$ We have a formal supplier certification program (Jup ated by digital automation without sen, dig

$l a_{4}$ Our suppliers are contractually committed to annual cost reductions by identifying abnormal product/operating conditions through sensors and IoT.

$l a_{5}$ We have corporate level communication on important issues with key suppliers aided by integrated digital interfaces and engineering systems through IoT

$l a_{6}$ We take active steps to reduce the number of suppliers in each category using collaborative engineering systems.

$l a_{7}$ We evaluate suppliers on the basis of total cost and not per unit price, identifying their product/operating conditions by means of digital sensors.

$l a_{8}$ Our customers are actively involved, through digital interfaces and remote control of production, in current and future product offerings.

$l a_{9}$ Our customers are directly involved in current and future product offerings through utilization of process-oriented technologies, such as digital automation, remote control sensors and integrated engineering systems.

$l a_{10}$ Our customers frequently share current and future demand information with marketing department utilizing integrated digital interfaces and engineering systems with sensors.

$l a_{11} \quad$ Production is pulled by the shipment of finished goods through integrated and collaborative systems.

$l a_{12}$ Production at stations is pulled by the current demand of the next station through integrated and collaborative systems.

$l a_{13}$ Products are classified into groups with similar processing requirements through integrated and collaborative engineering systems.

$l a_{14}$ Products are classified into groups with similar routing requirements through integrated and collaborative engineering systems.

$l a_{15}$ Equipment is grouped to produce a continuous flow of families of products through integrated and collaborative engineering systems.

$l a_{16}$ Families of products determine our factory layout through integrated and collaborative engineering systems.

$\begin{array}{ll}l a_{16} & \text { Families of products determine our factory layout through integrated and collaborative engineering systems. } \\ l a_{17} & \text { Our employees practice setups to reduce the time required supported by collaborative engineering systems. }\end{array}$

$\begin{array}{ll}l a_{17} & \text { ur employees practice setups to reduce the time required supported by collaborative engine } \\ l a_{18} & \text { We are working to lower setup times in our plant utilizing integrated engineering systems. }\end{array}$

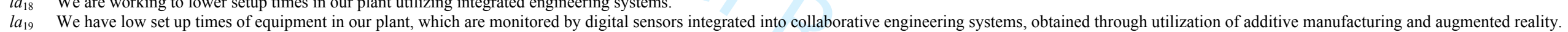

$l a_{20} \quad$ Large number of equipment/processes on shop floor are currently under statistical process control and monitored through digital sensors integrated into collaborative engineering systems.

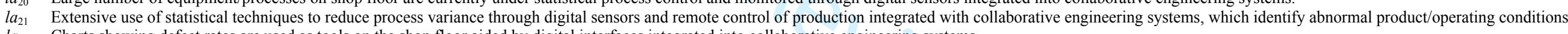

$l a_{22}$ Charts showing defect rates are used as tools on the shop floor aided by digital interfaces integrated into collaborative engineering systems.

$l a_{23}$ We use fishbone type diagrams aided by collaborative engineering systems to identify causes of quality problems.

$l a_{24}$ We conduct process capability studies aided by collaborative engineering systems before product launch.

$l a_{25}$ Shop floor employees drive suggestion programs utilizing machine digital interfaces integrated into collaborative engineering systems by means of IoT.

$l a_{26}$ Shop floor employees lead product/process improvement efforts based upon digital sensors, remote control of production and collaborative engineering systems.

$l a_{27}$ Shop floor employees undergo cross functional training utilizing digital interfaces, remote control of production, collaborative engineering systems to identify abnormal conditions, and IoT.

$l a_{28}$ We dedicate a portion of everyday to planned equipment maintenance related activities based upon data from digital sensors integrated into engineering systems, MES or SCADA.

$l a_{29} \quad$ We maintain all our equipment regularly using data collected from machine digital automation sensors.

$l a_{30}$ We maintain excellent records of all equipment maintenance related activities using data collected from machine digital automation sensors.

$l a_{31}$ We post equipment maintenance records on shop floor for active sharing with employees through machine digital interfaces integrated into collaborative engineering systems, MES or SCADA. 
Table 2 - LP and I4.0 competences

\begin{tabular}{|c|c|c|c|c|c|c|}
\hline & Consolidated Competences & $\begin{array}{r}\text { Seidel et } \\
\text { al. (2017) }\end{array}$ & $\begin{array}{l}\text { Camuffo and } \\
\text { Gerli (2018) }\end{array}$ & $\begin{array}{c}\text { Hecklau et } \\
\text { al. (2016) }\end{array}$ & $\begin{array}{l}\text { Grzybowska and } \\
\text { Eupicka (2017) }\end{array}$ & $\begin{array}{c}\text { Lupicka and } \\
\text { Grzybowska (2018) }\end{array}$ \\
\hline$c_{1}$ & Identify what adds value to internal and external clients & $\sqrt{ }$ & $\sqrt{1}$ & & & $\sqrt{ }$ \\
\hline$c_{2}$ & Identify and solve problems with their teams using the PDCA (Plan, Do, Check and Act) & $\sqrt{ }$ & $\sqrt{ }$ & $\sqrt{ }$ & $\checkmark$ & $\sqrt{ }$ \\
\hline$c_{3}$ & Use continuous improvement practices and principles & $\sqrt{ }$ & $\sqrt{ }$ & & & \\
\hline$c_{4}$ & Manage with emphasis on value flow rather than on isolated operations & $\checkmark$ & $\sqrt{ }$ & & & $\sqrt{ }$ \\
\hline$c_{5}$ & Provide value-added information clearly and objectively & $\sqrt{ }$ & $\mathfrak{v}$ & $\sqrt{ }$ & $\sqrt{ }$ & $\sqrt{ }$ \\
\hline$c_{6}$ & Put the group's interests above the individual ones & $\sqrt{ }$ & $\sqrt{ }$ & & $\sqrt{ }$ & $\sqrt{ }$ \\
\hline$c_{7}$ & Practice self-development as well as professional and personal continuous evolution & $\sqrt{ }$ & & $\sqrt{ }$ & $\mathfrak{v}$ & v \\
\hline$c_{8}$ & Identify and manage barriers during improvement initiatives implementation journey & $\sqrt{ }$ & $\sqrt{ }$ & $\sqrt{ }$ & & $\sqrt{ }$ \\
\hline$c_{9}$ & Practice continuous improvement as an interrelated system of principles and practices & $\sqrt{ }$ & $\sqrt{ }$ & & & \\
\hline$c_{10}$ & Develop actions that, based on ethical principles, respect the community, the environment and the workers' safety & $\sqrt{ }$ & & $\sqrt{ }$ & $\sqrt{ }$ & $\sqrt{ }$ \\
\hline$c_{11}$ & Develop innovative and challenging actions & $\sqrt{ }$ & & $\sqrt{ }$ & $\sqrt{ }$ & $\sqrt{ }$ \\
\hline$c_{12}$ & Develop computer programming/coding & & & $\sqrt{ }$ & $\sqrt{ }$ & $\sqrt{ }$ \\
\hline$c_{13}$ & Develop data processing and analytics & & & $\sqrt{ }$ & $\sqrt{ }$ & $\sqrt{ }$ \\
\hline$c_{14}$ & Put in practice statistical tools & & & $\sqrt{ }$ & $\sqrt{ }$ & $\sqrt{ }$ \\
\hline
\end{tabular}

Table 3 - Sample characteristics

\begin{tabular}{|c|c|c|c|c|c|}
\hline \multicolumn{3}{|c|}{ Respondents' Lean experience } & \multicolumn{3}{|c|}{ Company size } \\
\hline$<5$ years & 55 & $50.0 \%$ & $<500$ employees & 62 & $56.4 \%$ \\
\hline$>5$ years & 55 & $50.0 \%$ & $>500$ employees & 48 & $43.6 \%$ \\
\hline \multicolumn{3}{|c|}{ Respondents' I4.0 Knowledge } & \multicolumn{3}{|c|}{ Industry sector } \\
\hline Basic & 53 & $48.2 \%$ & Chemical & 13 & $11.8 \%$ \\
\hline Moderate/Advanced & 57 & $51.8 \%$ & Automotive & 13 & $11.8 \%$ \\
\hline \multicolumn{3}{|c|}{ Respondents' role } & Metal-mechanics & 12 & $10.9 \%$ \\
\hline Analyst/Engineer & 42 & $38.2 \%$ & Machine and equipment & 5 & $4.6 \%$ \\
\hline Supervisor/Coordinator & 35 & $31.8 \%$ & Textile & 5 & $4.6 \%$ \\
\hline Manager/Director & 33 & $30.0 \%$ & Food & 4 & $3.6 \%$ \\
\hline \multicolumn{3}{|l|}{ Tier level } & Others & 58 & $52.7 \%$ \\
\hline 1 or 2 & $\begin{array}{l}72 \\
38\end{array}$ & $65.5 \%$ & & & \\
\hline
\end{tabular}


Table 4 - Partial correlation between LA practices and competences using perceptions of practitioners with less than 5 years of LP experience $(n=55)$

\begin{tabular}{|c|c|c|c|c|c|c|c|c|c|c|c|c|c|c|c|}
\hline & $c_{1}$ & $c_{2}$ & $c_{3}$ & $c_{4}$ & $c_{5}$ & $c_{6}$ & $c_{7}$ & $c_{8}$ & $c_{9}$ & $c_{10}$ & $c_{11}$ & $c_{12}$ & $c_{13}$ & $c_{14}$ & $\mathrm{~N}^{\circ}$ of significant correlations \\
\hline$l a_{1}$ & & 0.308 & 0.319 & 0.274 & 0.354 & 0.280 & & & 0.279 & 0.308 & 0.385 & 0.524 & 0.454 & 0.591 & 11 \\
\hline$l a_{2}$ & 0.329 & 0.381 & 0.287 & & 0.353 & 0.301 & & & & & 0.292 & 0.453 & 0.460 & 0.464 & 9 \\
\hline$l a_{3}$ & 0.291 & 0.476 & 0.418 & 0.446 & 0.552 & 0.584 & 0.482 & 0.376 & 0.480 & 0.333 & 0.499 & 0.551 & 0.575 & 0.624 & 14 \\
\hline$l a_{4}$ & 0.548 & 0.367 & 0.271 & 0.398 & 0.488 & 0.606 & 0.505 & 0.381 & 0.352 & 0.271 & 0.469 & 0.447 & 0.448 & 0.478 & 14 \\
\hline$l a_{5}$ & 0.527 & 0.467 & 0.351 & 0.501 & 0.624 & 0.646 & 0.632 & 0.532 & 0.515 & 0.445 & 0.598 & 0.652 & 0.587 & 0.544 & 14 \\
\hline$l a_{6}$ & 0.450 & 0.478 & 0.324 & 0.550 & 0.637 & 0.628 & 0.459 & 0.613 & 0.588 & 0.330 & 0.485 & 0.546 & 0.636 & 0.494 & 14 \\
\hline$l a_{7}$ & 0.394 & 0.428 & & 0.498 & 0.527 & 0.492 & 0.325 & 0.406 & 0.417 & & & 0.364 & 0.536 & 0.370 & 11 \\
\hline$l a_{8}$ & 0.387 & 0.417 & 0.278 & 0.420 & 0.432 & 0.418 & 0.405 & 0.382 & 0.495 & 0.316 & 0.338 & 0.542 & 0.635 & 0.533 & 14 \\
\hline$l a_{9}$ & 0.441 & 0.496 & 0.397 & 0.579 & 0.606 & 0.515 & 0.439 & 0.446 & 0.581 & 0.473 & 0.458 & 0.503 & 0.636 & 0.577 & 14 \\
\hline$l a_{10}$ & 0.517 & 0.461 & 0.271 & 0.552 & 0.654 & 0.605 & 0.443 & 0.511 & 0.473 & 0.368 & 0.400 & 0.355 & 0.551 & 0.397 & 14 \\
\hline$l a_{11}$ & 0.402 & 0.502 & 0.333 & 0.303 & 0.354 & 0.381 & 0.344 & & 0.270 & 0.278 & & 0.473 & 0.488 & 0.547 & 12 \\
\hline$l a_{12}$ & 0.414 & 0.621 & 0.496 & 0.418 & 0.488 & 0.472 & 0.382 & & 0.359 & 0.424 & 0.415 & 0.652 & 0.655 & 0.718 & 13 \\
\hline$l a_{13}$ & 0.345 & 0.582 & 0.440 & 0.396 & 0.547 & 0.468 & 0.355 & 0.390 & 0.418 & 0.348 & 0.371 & 0.496 & 0.704 & 0.587 & 14 \\
\hline$l a_{14}$ & 0.305 & 0.601 & 0.369 & 0.419 & 0.583 & 0.498 & 0.365 & 0.391 & 0.341 & 0.288 & 0.373 & 0.492 & 0.709 & 0.531 & 14 \\
\hline$l a_{15}$ & 0.374 & 0.439 & 0.462 & 0.497 & 0.400 & 0.358 & & & 0.428 & 0.377 & & 0.440 & 0.589 & 0.571 & 11 \\
\hline$l a_{16}$ & 0.462 & 0.649 & 0.564 & 0.492 & 0.528 & 0.442 & 0.373 & & 0.411 & 0.548 & 0.480 & 0.661 & 0.667 & 0.719 & 13 \\
\hline$l a_{17}$ & 0.500 & 0.585 & 0.452 & 0.407 & 0.529 & 0.432 & 0.468 & & 0.333 & 0.494 & 0.282 & 0.451 & 0.430 & 0.435 & 13 \\
\hline$l a_{18}$ & 0.336 & 0.517 & 0.478 & 0.381 & 0.421 & 0.297 & & & 0.351 & 0.434 & 0.309 & 0.530 & 0.608 & 0.570 & 12 \\
\hline$l a_{19}$ & 0.329 & 0.358 & 0.272 & 0.221 & & & & & & & & 0.296 & 0.381 & 0.419 & 7 \\
\hline$l a_{20}$ & & 0.310 & & & 0.310 & & & & 0.271 & 0.284 & 0.292 & 0.490 & 0.657 & 0.524 & 8 \\
\hline$l a_{21}$ & & 0.352 & & & 0.277 & & & & & & & 0.470 & 0.639 & 0.446 & 5 \\
\hline$l a_{22}$ & 0.432 & 0.475 & 0.386 & 0.340 & 0.413 & 0.422 & 0.445 & & 0.289 & 0.369 & 0.270 & 0.471 & 0.523 & 0.538 & 13 \\
\hline$l a_{23}$ & 0.286 & 0.464 & 0.445 & 0.437 & 0.423 & 0.323 & 0.467 & 0.279 & 0.483 & 0.550 & 0.332 & 0.603 & 0.541 & 0.560 & 14 \\
\hline$l a_{24}$ & 0.429 & 0.472 & 0.483 & 0.402 & 0.399 & 0.399 & 0.375 & & 0.330 & 0.496 & 0.340 & 0.386 & 0.460 & 0.565 & 13 \\
\hline$l a_{25}$ & 0.354 & 0.347 & 0.288 & 0.335 & 0.373 & 0.327 & 0.284 & & & 0.394 & 0.325 & 0.446 & 0.528 & 0.489 & 12 \\
\hline$l a_{26}$ & 0.440 & 0.393 & 0.353 & 0.455 & 0.464 & 0.427 & 0.274 & 0.285 & 0.362 & 0.360 & 0.388 & 0.519 & 0.570 & 0.599 & 14 \\
\hline$l a_{27}$ & 0.404 & 0.474 & 0.453 & 0.441 & 0.418 & 0.448 & 0.446 & 0.279 & 0.406 & 0.380 & 0.335 & 0.631 & 0.593 & 0.641 & 14 \\
\hline$l a_{28}$ & 0.478 & 0.562 & 0.500 & 0.361 & 0.422 & 0.374 & 0.513 & & 0.281 & 0.467 & & 0.603 & 0.407 & 0.577 & 12 \\
\hline$l a_{29}$ & 0.275 & 0.435 & 0.413 & 0.382 & 0.458 & 0.433 & 0.520 & 0.352 & 0.505 & 0.507 & 0.452 & 0.667 & 0.597 & 0.637 & 14 \\
\hline$l a_{30}$ & 0.427 & 0.490 & 0.441 & 0.430 & 0.546 & 0.508 & 0.529 & 0.417 & 0.530 & 0.479 & 0.420 & 0.651 & 0.568 & 0.586 & 14 \\
\hline$l a_{31}$ & 0.575 & 0.486 & 0.428 & 0.417 & 0.414 & 0.498 & 0.591 & 0.329 & 0.347 & 0.345 & 0.345 & 0.632 & 0.367 & 0.567 & 14 \\
\hline $\mathrm{N}^{\circ}$ of significant correlations & 28 & 31 & 28 & 28 & 30 & 28 & 24 & 16 & 27 & 27 & 25 & 31 & 31 & 31 & 385 \\
\hline
\end{tabular}

Note: Only significant partial correlation coefficients were reported $(p$-value $<0.05)$. Gray cells indicate strong partial correlation (i.e. coefficients $>0.7)$. 
Table 5 - Partial correlation between LA practices and competences using perceptions of practitioners with more than 5 years of LP experience $(n=55)$

\begin{tabular}{|c|c|c|c|c|c|c|c|c|c|c|c|c|c|c|c|}
\hline & $c_{1}$ & $c_{2}$ & $c_{3}$ & $c_{4}$ & $c_{5}$ & $c_{6}$ & $c_{7}$ & $c_{8}$ & $c_{9}$ & $c_{10}$ & $c_{11}$ & $c_{12}$ & $c_{13}$ & $c_{14}$ & $\mathrm{~N}^{\circ}$ of significant correlations \\
\hline$l a_{1}$ & 0.437 & 0.509 & 0.438 & 0.481 & 0.543 & 0.462 & 0.400 & 0.471 & 0.440 & 0.305 & 0.637 & 0.710 & 0.509 & 0.619 & 14 \\
\hline$l a_{2}$ & 0.490 & 0.378 & 0.318 & 0.291 & 0.453 & 0.420 & 0.380 & 0.423 & 0.286 & & 0.473 & 0.495 & 0.470 & 0.336 & 13 \\
\hline $\mathrm{la}_{3}$ & 0.501 & 0.529 & 0.450 & 0.545 & 0.567 & 0.605 & 0.585 & 0.511 & 0.489 & 0.354 & 0.607 & 0.566 & 0.447 & 0.489 & 14 \\
\hline$l a_{4}$ & 0.542 & 0.357 & 0.283 & 0.288 & 0.441 & 0.508 & 0.386 & 0.382 & & & 0.426 & 0.409 & 0.462 & 0.402 & 12 \\
\hline$l a_{5}$ & 0.517 & 0.525 & 0.398 & 0.618 & 0.708 & 0.619 & 0.725 & 0.504 & 0.506 & 0.351 & 0.559 & 0.715 & 0.567 & 0.634 & 14 \\
\hline$l a_{6}$ & 0.598 & 0.569 & 0.461 & 0.662 & 0.783 & 0.766 & 0.636 & 0.727 & 0.649 & 0.429 & 0.699 & 0.588 & 0.636 & 0.589 & 14 \\
\hline$l a_{7}$ & 0.312 & 0.402 & & 0.518 & 0.601 & 0.534 & 0.504 & 0.457 & 0.468 & & 0.394 & 0.406 & 0.408 & & 11 \\
\hline$l a_{8}$ & 0.479 & 0.379 & 0.356 & 0.316 & 0.405 & 0.448 & 0.341 & 0.391 & 0.347 & & 0.463 & 0.479 & 0.536 & 0.381 & 13 \\
\hline$l a_{9}$ & 0.469 & 0.623 & 0.447 & 0.725 & 0.769 & 0.714 & 0.645 & 0.590 & 0.672 & 0.469 & 0.622 & 0.624 & 0.531 & 0.535 & 14 \\
\hline$l a_{10}$ & 0.399 & 0.458 & & 0.581 & 0.666 & 0.584 & 0.534 & 0.474 & 0.448 & 0.301 & 0.382 & 0.446 & 0.516 & 0.399 & 13 \\
\hline$l a_{11}$ & 0.594 & 0.502 & 0.386 & 0.350 & 0.453 & 0.474 & 0.472 & 0.444 & 0.307 & & 0.481 & 0.457 & 0.382 & 0.466 & 13 \\
\hline$l a_{12}$ & 0.445 & 0.497 & 0.449 & 0.429 & 0.461 & 0.404 & 0.485 & 0.382 & 0.372 & 0.320 & 0.511 & 0.650 & 0.432 & 0.564 & 14 \\
\hline$l a_{13}$ & 0.589 & 0.365 & 0.373 & & 0.492 & 0.479 & 0.370 & 0.539 & & 0.304 & 0.535 & 0.394 & 0.584 & 0.453 & 12 \\
\hline$l a_{14}$ & 0.354 & 0.414 & & 0.428 & 0.694 & 0.465 & 0.476 & 0.467 & 0.396 & & 0.501 & 0.632 & 0.603 & 0.528 & 12 \\
\hline$l a_{15}$ & 0.507 & 0.359 & 0.439 & 0.380 & 0.463 & 0.370 & & 0.427 & 0.332 & 0.290 & 0.505 & 0.449 & 0.470 & 0.465 & 13 \\
\hline$l a_{16}$ & 0.568 & 0.593 & 0.607 & 0.467 & 0.505 & 0.477 & 0.388 & 0.388 & 0.335 & 0.475 & 0.605 & 0.538 & 0.437 & 0.535 & 14 \\
\hline$l a_{17}$ & 0.646 & 0.637 & 0.487 & 0.463 & 0.644 & 0.560 & 0.626 & 0.462 & 0.362 & 0.508 & 0.527 & 0.409 & 0.345 & 0.295 & 14 \\
\hline$l a_{18}$ & 0.596 & 0.527 & 0.599 & 0.436 & 0.491 & 0.533 & 0.413 & 0.513 & 0.413 & 0.583 & 0.651 & 0.465 & 0.551 & 0.484 & 14 \\
\hline$l a_{19}$ & 0.419 & 0.464 & 0.295 & 0.321 & 0.330 & 0.378 & 0.404 & & & & 0.321 & 0.465 & 0.505 & 0.337 & 11 \\
\hline$l a_{20}$ & 0.425 & & & & 0.281 & & & 0.278 & & & 0.345 & 0.460 & 0.626 & 0.463 & 7 \\
\hline$l a_{21}$ & 0.449 & 0.322 & & & 0.325 & 0.288 & 0.299 & 0.311 & & & 0.354 & 0.507 & 0.617 & 0.472 & 10 \\
\hline$l a_{22}$ & 0.742 & 0.472 & 0.447 & 0.306 & 0.411 & 0.499 & 0.467 & 0.334 & & 0.339 & 0.436 & 0.317 & 0.405 & 0.396 & 13 \\
\hline$l a_{23}$ & 0.564 & 0.583 & 0.548 & 0.638 & 0.609 & 0.515 & 0.693 & 0.455 & 0.556 & 0.573 & 0.518 & 0.575 & 0.364 & 0.612 & 14 \\
\hline$l a_{24}$ & 0.742 & 0.509 & 0.565 & 0.379 & 0.419 & 0.473 & 0.327 & 0.486 & & 0.483 & 0.549 & & 0.347 & 0.453 & 12 \\
\hline$l a_{25}$ & 0.592 & 0.405 & 0.384 & 0.321 & 0.390 & 0.520 & 0.373 & & & 0.433 & 0.374 & 0.286 & 0.531 & 0.362 & 12 \\
\hline$l a_{26}$ & 0.550 & 0.356 & 0.347 & 0.438 & 0.501 & 0.444 & 0.360 & 0.417 & 0.317 & 0.270 & 0.502 & 0.558 & 0.532 & 0.599 & 14 \\
\hline$l a_{27}$ & 0.576 & 0.345 & 0.364 & 0.307 & 0.412 & 0.397 & 0.481 & 0.402 & & & 0.488 & 0.585 & 0.502 & 0.537 & 12 \\
\hline$l a_{28}$ & 0.664 & 0.511 & 0.507 & 0.360 & 0.460 & 0.462 & 0.594 & 0.324 & & 0.452 & 0.482 & 0.624 & 0.510 & 0.578 & 13 \\
\hline$l a_{29}$ & 0.582 & 0.426 & 0.451 & 0.362 & 0.503 & 0.459 & 0.545 & 0.443 & 0.375 & 0.407 & 0.510 & 0.688 & 0.639 & 0.693 & 14 \\
\hline$l a_{30}$ & 0.636 & 0.399 & 0.396 & & 0.434 & 0.454 & 0.452 & 0.451 & & 0.347 & 0.474 & 0.559 & 0.574 & 0.553 & 12 \\
\hline$l a_{31}$ & 0.714 & 0.369 & 0.371 & 0.282 & 0.428 & 0.487 & 0.561 & 0.414 & & 0.286 & 0.504 & 0.574 & 0.436 & 0.537 & 13 \\
\hline $\mathrm{N}^{\circ}$ of significant correlations & 31 & 30 & 26 & 27 & 31 & 30 & 29 & 29 & 19 & 21 & 31 & 30 & 31 & 30 & 395 \\
\hline
\end{tabular}

Note: Only significant partial correlation coefficients were reported ( $p$-value $<0.05$ ). Gray cells indicate strong partial correlation (i.e. coefficients $>0.7)$ 
Table 6 - Partial correlation between LA practices and competences using perceptions of practitioners with Basic knowledge on I4.0 $(n=53)$

\begin{tabular}{|c|c|c|c|c|c|c|c|c|c|c|c|c|c|c|c|}
\hline & $c_{1}$ & $c_{2}$ & $c_{3}$ & $c_{4}$ & $c_{5}$ & $c_{6}$ & $c_{7}$ & $c_{8}$ & $c_{9}$ & $c_{10}$ & $c_{11}$ & $c_{12}$ & $c_{13}$ & $c_{14}$ & $\mathrm{~N}^{\circ}$ of significant correlations \\
\hline$l a_{1}$ & 0.299 & 0.346 & 0.366 & 0.357 & 0.418 & 0.335 & & 0.291 & 0.353 & 0.339 & 0.487 & 0.583 & 0.479 & 0.604 & 13 \\
\hline$l a_{2}$ & 0.389 & 0.305 & 0.301 & & 0.370 & 0.340 & & 0.293 & & & 0.353 & 0.444 & 0.481 & 0.397 & 10 \\
\hline$l a_{3}$ & 0.377 & 0.423 & 0.433 & 0.435 & 0.554 & 0.602 & 0.491 & 0.468 & 0.488 & 0.388 & 0.562 & 0.542 & 0.539 & 0.556 & 14 \\
\hline$l a_{4}$ & 0.522 & 0.335 & 0.316 & 0.326 & 0.467 & 0.571 & 0.430 & 0.411 & 0.289 & 0.307 & 0.479 & 0.451 & 0.509 & 0.469 & 14 \\
\hline$l a_{5}$ & 0.460 & 0.433 & 0.360 & 0.538 & 0.666 & 0.626 & 0.656 & 0.513 & 0.525 & 0.431 & 0.577 & 0.732 & 0.621 & 0.618 & 14 \\
\hline$l a_{6}$ & 0.449 & 0.390 & 0.315 & 0.540 & 0.650 & 0.642 & 0.454 & 0.621 & 0.558 & 0.329 & 0.525 & 0.563 & 0.663 & 0.512 & 14 \\
\hline$l a_{7}$ & 0.309 & 0.289 & & 0.451 & 0.521 & 0.472 & 0.355 & 0.402 & 0.406 & & 0.315 & 0.422 & 0.470 & 0.330 & 12 \\
\hline$l a_{8}$ & 0.445 & 0.335 & 0.283 & 0.356 & 0.439 & 0.449 & 0.353 & 0.443 & 0.409 & 0.287 & 0.485 & 0.491 & 0.607 & 0.437 & 14 \\
\hline$l a_{9}$ & 0.374 & 0.403 & 0.339 & 0.594 & 0.660 & 0.574 & 0.494 & 0.505 & 0.602 & 0.451 & 0.569 & 0.588 & 0.652 & 0.583 & 14 \\
\hline$l a_{10}$ & 0.444 & 0.387 & & 0.573 & 0.697 & 0.650 & 0.517 & 0.541 & 0.518 & 0.357 & 0.481 & 0.496 & 0.599 & 0.485 & 13 \\
\hline$l a_{11}$ & 0.503 & 0.418 & 0.331 & 0.279 & 0.365 & 0.395 & 0.409 & 0.297 & & 0.305 & 0.369 & 0.521 & 0.447 & 0.532 & 13 \\
\hline$l a_{12}$ & 0.464 & 0.479 & 0.431 & 0.375 & 0.485 & 0.452 & 0.484 & 0.321 & 0.343 & 0.399 & 0.458 & 0.718 & 0.551 & 0.673 & 14 \\
\hline$l a_{13}$ & 0.469 & 0.386 & 0.375 & & 0.479 & 0.460 & 0.350 & 0.446 & 0.312 & 0.339 & 0.443 & 0.502 & 0.672 & 0.538 & 13 \\
\hline$l a_{14}$ & 0.276 & 0.401 & & 0.375 & 0.579 & 0.431 & 0.403 & 0.390 & 0.330 & & 0.394 & 0.586 & 0.626 & 0.531 & 12 \\
\hline$l a_{15}$ & 0.461 & 0.277 & 0.401 & 0.362 & 0.412 & 0.410 & & 0.336 & 0.324 & 0.340 & 0.420 & 0.448 & 0.559 & 0.542 & 13 \\
\hline$l a_{16}$ & 0.550 & 0.516 & 0.542 & 0.393 & 0.519 & 0.473 & 0.405 & 0.291 & 0.319 & 0.551 & 0.566 & 0.624 & 0.554 & 0.639 & 14 \\
\hline$l a_{17}$ & 0.501 & 0.507 & 0.414 & 0.324 & 0.478 & 0.419 & 0.475 & & & 0.450 & 0.345 & 0.435 & 0.329 & 0.364 & 12 \\
\hline$l a_{18}$ & 0.498 & 0.408 & 0.475 & 0.326 & 0.403 & 0.393 & & 0.301 & 0.308 & 0.463 & 0.422 & 0.504 & 0.571 & 0.500 & 13 \\
\hline$l a_{19}$ & 0.398 & 0.357 & 0.311 & & 0.280 & 0.302 & 0.359 & & & 0.308 & 0.299 & 0.355 & 0.397 & 0.420 & 11 \\
\hline$l a_{20}$ & 0.369 & & & & 0.326 & 0.348 & 0.280 & 0.329 & & 0.297 & 0.427 & 0.511 & 0.674 & 0.538 & 10 \\
\hline$l a_{21}$ & 0.359 & 0.307 & & & 0.312 & 0.307 & & & & & 0.324 & 0.472 & 0.629 & 0.454 & 8 \\
\hline$l a_{22}$ & 0.613 & 0.453 & 0.458 & 0.326 & 0.403 & 0.497 & 0.462 & 0.284 & & 0.445 & 0.427 & 0.450 & 0.497 & 0.534 & 13 \\
\hline$l a_{23}$ & 0.408 & 0.438 & 0.424 & 0.466 & 0.497 & 0.433 & 0.603 & 0.332 & 0.470 & 0.567 & 0.448 & 0.660 & 0.465 & 0.627 & 14 \\
\hline$l a_{24}$ & 0.600 & 0.435 & 0.505 & 0.308 & 0.363 & 0.489 & 0.346 & 0.339 & 0.230 & 0.533 & 0.486 & 0.354 & 0.463 & 0.550 & 14 \\
\hline$l a_{25}$ & 0.502 & 0.312 & 0.344 & 0.276 & 0.357 & 0.475 & 0.347 & & & 0.494 & 0.466 & 0.385 & 0.553 & 0.474 & 12 \\
\hline$l a_{26}$ & 0.509 & 0.317 & 0.352 & 0.409 & 0.476 & 0.498 & 0.344 & 0.368 & 0.341 & 0.361 & 0.506 & 0.570 & 0.573 & 0.643 & 14 \\
\hline$l a_{27}$ & 0.540 & 0.376 & 0.421 & 0.332 & 0.400 & 0.485 & 0.467 & 0.339 & 0.295 & 0.379 & 0.432 & 0.607 & 0.545 & 0.617 & 14 \\
\hline$l a_{28}$ & 0.606 & 0.530 & 0.533 & 0.333 & 0.413 & 0.444 & 0.564 & & & 0.498 & 0.366 & 0.603 & 0.394 & 0.586 & 12 \\
\hline$l a_{29}$ & 0.433 & 0.378 & 0.391 & 0.333 & 0.447 & 0.477 & 0.549 & 0.413 & 0.422 & 0.512 & 0.544 & 0.686 & 0.599 & 0.663 & 14 \\
\hline$l a_{30}$ & 0.576 & 0.427 & 0.446 & 0.324 & 0.492 & 0.555 & 0.495 & 0.464 & 0.382 & 0.496 & 0.522 & 0.592 & 0.579 & 0.567 & 14 \\
\hline$l a_{31}$ & 0.680 & 0.446 & 0.486 & 0.355 & 0.415 & 0.554 & 0.574 & 0.365 & & 0.430 & 0.440 & 0.589 & 0.383 & 0.581 & 13 \\
\hline $\mathrm{N}^{\circ}$ of significant correlations & 31 & 30 & 26 & 26 & 31 & 31 & 26 & 26 & 21 & 27 & 31 & 31 & 31 & 31 & 399 \\
\hline
\end{tabular}

Note: Only significant partial correlation coefficients were reported $(p$-value $<0.05$ ). Gray cells indicate strong partial correlation (i.e. coefficients $>0.7)$. 
Table 7 - Partial correlation between LA practices and competences using perceptions of practitioners with Moderate or Advanced knowledge on I4.0 $(n=57)$

\begin{tabular}{|c|c|c|c|c|c|c|c|c|c|c|c|c|c|c|c|}
\hline & $c_{1}$ & $c_{2}$ & $c_{3}$ & $c_{4}$ & $c_{5}$ & $c_{6}$ & $c_{7}$ & $c_{8}$ & $c_{9}$ & $c_{10}$ & $c_{11}$ & $c_{12}$ & $c_{13}$ & $c_{14}$ & $\mathrm{~N}^{\circ}$ of significant correlations \\
\hline$l a_{1}$ & & 0.405 & 0.373 & 0.357 & 0.406 & 0.323 & & & 0.299 & & 0.485 & 0.590 & 0.379 & 0.563 & 10 \\
\hline$l a_{2}$ & 0.412 & 0.404 & 0.314 & & 0.363 & 0.322 & 0.334 & & & & 0.388 & 0.435 & 0.345 & 0.351 & 10 \\
\hline$l a_{3}$ & 0.411 & 0.576 & 0.464 & 0.545 & 0.541 & 0.563 & 0.535 & 0.389 & 0.423 & 0.309 & 0.539 & 0.506 & 0.383 & 0.537 & 14 \\
\hline$l a_{4}$ & 0.534 & 0.318 & 0.241 & 0.321 & 0.388 & 0.494 & 0.392 & & & & 0.369 & 0.360 & 0.345 & 0.408 & 11 \\
\hline$l a_{5}$ & 0.521 & 0.489 & 0.341 & 0.517 & 0.593 & 0.547 & 0.668 & 0.444 & 0.426 & 0.307 & 0.504 & 0.630 & 0.438 & 0.542 & 14 \\
\hline$l a_{6}$ & 0.538 & 0.597 & 0.451 & 0.633 & 0.717 & 0.698 & 0.584 & 0.689 & 0.654 & 0.413 & 0.619 & 0.549 & 0.563 & 0.570 & 14 \\
\hline$l a_{7}$ & 0.332 & 0.474 & 0.320 & 0.566 & 0.557 & 0.487 & 0.411 & 0.408 & 0.460 & & 0.306 & 0.335 & 0.426 & 0.314 & 13 \\
\hline$l a_{8}$ & 0.348 & 0.354 & 0.338 & 0.326 & & & 0.314 & & 0.365 & & & 0.507 & 0.511 & 0.458 & 9 \\
\hline$l a_{9}^{\circ}$ & 0.495 & 0.629 & 0.509 & 0.707 & 0.665 & 0.569 & 0.543 & 0.466 & 0.612 & 0.472 & 0.461 & 0.502 & 0.444 & 0.540 & 14 \\
\hline$l a_{10}$ & 0.388 & 0.430 & & 0.530 & 0.541 & 0.440 & 0.392 & 0.356 & 0.347 & & & 0.299 & 0.422 & 0.353 & 11 \\
\hline$l a_{11}$ & 0.449 & 0.567 & 0.414 & 0.333 & 0.370 & 0.389 & 0.407 & 0.344 & 0.321 & & & 0.403 & 0.344 & 0.471 & 12 \\
\hline$l a_{12}$ & 0.333 & 0.603 & 0.501 & 0.416 & 0.396 & 0.342 & 0.364 & & 0.333 & 0.302 & 0.382 & 0.545 & 0.428 & 0.558 & 13 \\
\hline$l a_{13}$ & 0.378 & 0.578 & 0.416 & 0.301 & 0.520 & 0.446 & 0.367 & 0.461 & 0.341 & & 0.369 & 0.359 & 0.575 & 0.451 & 13 \\
\hline$l a_{14}$ & & 0.575 & 0.323 & 0.426 & 0.661 & 0.479 & 0.406 & 0.407 & 0.339 & & 0.432 & 0.505 & 0.663 & 0.532 & 12 \\
\hline$l a_{15}$ & 0.383 & 0.470 & 0.500 & 0.498 & 0.386 & & & 0.305 & 0.424 & 0.303 & & 0.372 & 0.400 & 0.433 & 11 \\
\hline$l a_{16}$ & 0.428 & 0.690 & 0.619 & 0.525 & 0.460 & 0.372 & 0.334 & & 0.389 & 0.454 & 0.449 & 0.544 & 0.472 & 0.556 & 13 \\
\hline$l a_{17}$ & 0.624 & 0.660 & 0.547 & 0.478 & 0.626 & 0.458 & 0.601 & 0.387 & 0.367 & 0.573 & 0.403 & 0.432 & 0.379 & 0.357 & 14 \\
\hline$l a_{18}$ & 0.384 & 0.608 & 0.576 & 0.425 & 0.460 & 0.362 & & 0.394 & 0.433 & 0.535 & 0.456 & 0.470 & 0.501 & 0.477 & 13 \\
\hline$l a_{19}$ & & 0.385 & & & & & & & & & & 0.359 & 0.407 & 0.349 & 4 \\
\hline$l a_{20}$ & & & & & & & & & & & & 0.426 & 0.540 & 0.383 & 3 \\
\hline$l a_{21}$ & & 0.354 & & & & & & & & & & 0.506 & 0.595 & 0.470 & 4 \\
\hline$l a_{22}$ & 0.521 & 0.472 & 0.404 & & 0.354 & 0.321 & 0.419 & & & & & 0.315 & 0.352 & 0.399 & 9 \\
\hline$l a_{23}$ & 0.389 & 0.574 & 0.516 & 0.524 & 0.454 & & 0.545 & 0.336 & 0.519 & 0.518 & & 0.511 & 0.334 & 0.488 & 12 \\
\hline$l a_{24}$ & 0.548 & 0.545 & 0.544 & 0.426 & 0.380 & 0.322 & 0.319 & 0.346 & 0.297 & 0.452 & 0.326 & & & 0.398 & 12 \\
\hline$l_{25}^{24}$ & 0.392 & 0.416 & 0.341 & 0.343 & 0.347 & 0.303 & & & & 0.335 & & 0.328 & 0.426 & 0.373 & 10 \\
\hline$l a_{26}$ & 0.452 & 0.396 & 0.364 & 0.478 & 0.440 & 0.330 & & 0.301 & 0.329 & & 0.330 & 0.480 & 0.429 & 0.569 & 12 \\
\hline$l a_{27}$ & 0.413 & 0.445 & 0.408 & 0.381 & 0.383 & 0.302 & 0.461 & 0.308 & 0.337 & & 0.317 & 0.602 & 0.464 & 0.539 & 13 \\
\hline$l a_{28}$ & 0.434 & 0.482 & 0.410 & & 0.356 & & 0.507 & & & 0.370 & & 0.601 & 0.415 & 0.496 & 9 \\
\hline$l a_{29}$ & 0.335 & 0.452 & 0.396 & 0.295 & 0.430 & 0.310 & 0.490 & & 0.372 & 0.348 & & 0.635 & 0.574 & 0.607 & 12 \\
\hline$l a_{30}$ & 0.413 & 0.395 & 0.325 & & 0.381 & & 0.434 & 0.309 & & & & 0.591 & 0.496 & 0.530 & 9 \\
\hline$l a_{31}$ & 0.552 & 0.370 & 0.316 & & 0.345 & 0.333 & 0.536 & & & & & 0.583 & 0.343 & 0.509 & 9 \\
\hline $\mathrm{N}^{\circ}$ of significant correlations & 26 & 30 & 27 & 23 & 27 & 23 & 23 & 17 & 21 & 14 & 17 & 30 & 30 & 31 & 339 \\
\hline
\end{tabular}

Note: Only significant partial correlation coefficients were reported $(p$-value $<0.05$ ). Gray cells indicate strong partial correlation (i.e. coefficients $>0.7$ ). 
Table 8 - Consolidation of the pairwise partial correlation between LA practices and competences

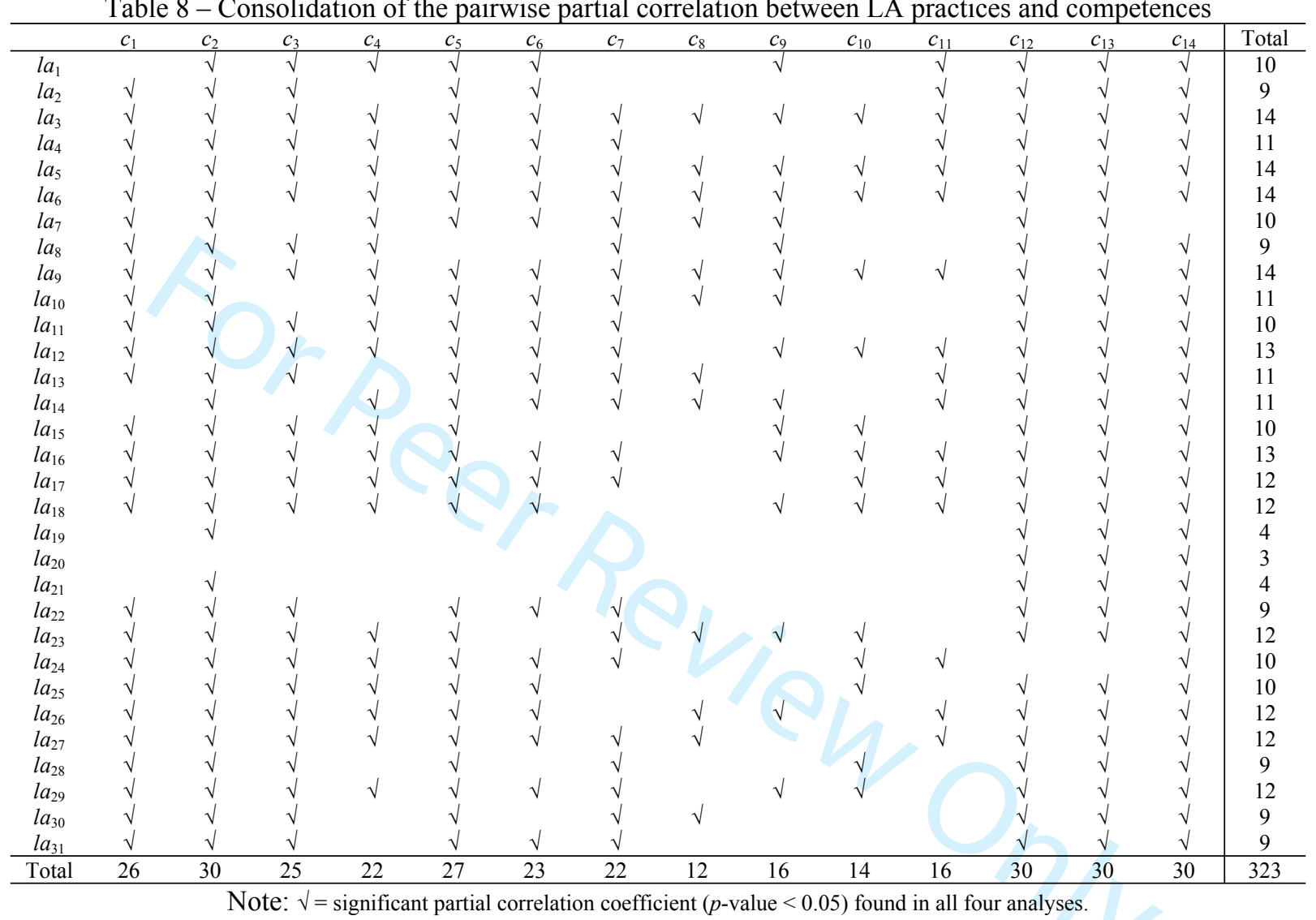

